\title{
Evidence That Geographic Variation in Genetic Ancestry Associates With Uterine Fibroids
}

Jacob M. Keaton

$\mathrm{NIH}$ : National Institutes of Health

Elizabeth A Jasper

Vanderbilt University Medical Center https://orcid.org/0000-0003-2444-0951

Jacklyn N. Hellwege

Vanderbilt University Medical Center

Sarah H. Jones

Vanderbilt University Medical Center

Eric S. Torstenson

Vanderbilt University Medical Center

Todd L. Edwards

Vanderbilt University Medical Center

Digna R. Velez Edwards ( $\square$ digna.r.velez.edwards@vumc.org )

Vanderbilt University Medical Center

\section{Research Article}

Keywords: leiomyoma, genetic ancestry, reproductive genetics, gynecology

Posted Date: May 13th, 2021

DOI: https://doi.org/10.21203/rs.3.rs-500189/v1

License: (c) (1) This work is licensed under a Creative Commons Attribution 4.0 International License.

Read Full License

Version of Record: A version of this preprint was published at Human Genetics on July 23rd, 2021. See the published version at https://doi.org/10.1007/s00439-021-02322-y. 


\section{Abstract}

Uterine fibroids disproportionately impact African American (AA) women. Evidence suggests AA women have earlier onset and higher cumulative risk. This risk disparity may be due an imbalance of risk alleles in one parental geographic subpopulation relative to others. We investigated ancestry proportions for the 1000 Genomes phase 3 populations clustered into 6 geographic groups for association with fibroid traits in AA women ( $n=583$ cases, 797 controls) and European American (EA) women ( $n=1,195$ cases, 1,164 controls). Global ancestry proportions were estimated using ADMIXTURE. Dichotomous (fibroids status and multiple fibroid status) and continuous outcomes (volume and largest dimension) were modeled for association with ancestry proportions using logistic and linear regression adjusting for age. Effect estimates are reported per $10 \%$ increase in genetically inferred ancestry proportion. Among AAs, West African (WAFR) ancestry was associated with fibroid risk, East African ancestry was associated with risk of multiple fibroids, Northern European (NEUR) ancestry was protective for multiple fibroids, Southern European ancestry was protective for fibroids and multiple fibroids, and South Asian (SAS) ancestry was positively associated with volume and largest dimension. In EAs, NEUR ancestry was protective for fibroids, SAS ancestry was associated with fibroid risk, and WAFR ancestry was positively associated with volume and largest dimension. These results suggest that a proportion of fibroid risk and fibroid trait racial disparities are due to genetic differences between geographic groups. Further investigation at the local ancestry and single variant levels may yield novel insights about disease architecture and genetic mechanisms underlying ethnic disparities in fibroid risk.

\section{Introduction}

Uterine fibroids, or leiomyomata, are benign smooth muscle neoplasms of the uterus and are the most common benign tumors among women of reproductive age(Wallach and Vlahos, 2004). Fibroid incidence increases with age ranging from $20 \%$ after menarche up to $80 \%$ by the onset of menopause(Baird et al., 2003, Cramer and Patel, 1990, Laughlin et al., 2009, Lippman et al., 2003, Marshall et al., 1997, Zimmermann et al., 2012). Fibroids are the leading indication of hysterectomy (39\%) and estimates of healthcare costs range from \$5.9-34.4 billion annually in the United States (US)(Cardozo et al., 2012, Whiteman et al., 2008). Clinical and epidemiology studies have identified numerous predisposing risk factors that may play a role in the pathogenesis. Genetics appear to play a major role. Women with firstdegree relatives with fibroids have an increased risk of developing fibroids compared to those without a family history (Sato et al., 2002, Vikhlyaeva et al., 1995). Race and ethnicity are the biggest risk factors for the development. Yet, the contribution of genetic ancestry to fibroid risk has been unclear.

Black women are disproportionately impacted by fibroids(Ross et al., 1986, Ryan et al., 2005). They are two to three times more likely to be diagnosed with fibroids compared to White women, and carry an increased risk for an earlier age-at-diagnosis, as well as an increased risk for larger and more numerous fibroids(Baird, Dunson, Hill, Cousins and Schectman, 2003, Kjerulff et al., 1996, Laughlin, Baird, Savitz, Herring and Hartmann, 2009, Marshall, Spiegelman, Barbieri, Goldman, Manson, Colditz, Willett and 
Hunter, 1997). Black women are also more likely to have a hysterectomy or myomectomy to treat fibroids(Wechter et al., 2011).

Previous studies have shown that risk of fibroproliferative disease including keloids(Niessen et al., 1999), glaucoma(Morris et al., 1999, Racette et al., 2003), hypertension(Dustan, 1992, Suthanthiran et al., 2000), nephrosclerosis(August and Suthanthiran, 2003), scleroderma(Mayes et al., 2003), sarcoidosis(Rybicki et al., 1998), asthma(Barnes et al., 2007, Lester et al., 2001, Newth et al., 2012, Nickel et al., 1999), and fibroids(Flake et al., 2003), varies by race/ethnicity. Further supporting this are findings from our group that demonstrated that the frequency of fibroproliferative risk alleles varies by geographic ancestry with a much higher burden among African-ancestry populations and lower among European-derived populations(Hellwege et al., 2017). Admixture mapping analysis of fibroid risk and multiple fibroid risk also demonstrates increased risk among Black women compared to White women(Bray et al., 2017, Giri et al., 2017).

Evidence suggests that adaptive variation conferring evolutionary advantages in tropical environments inhabited by ancestral African populations, such as connective tissue overgrowth in wound repair and hyperpigmentation as a response to ultraviolet radiation damage, may increase risk for multiple complex diseases in modern African-derived populations(Hellwege et al., 2017, Polednak, 1987). Russell et al postulated that variation protective for helminth infection may account for increased risk of fibroproliferative disease in African populations(Russell et al., 2015). It is unclear if genetic variation underlying fibroid risk or conferring protection against the development of fibroids has geographic origins beyond continental Africa. Defining the relationship between biogeographic ancestry and fibroid risk can provide information on the burden of genetic risk factors across ancestry groups and can illustrate differences between genetic ancestries within race and ethnicity groups.

We investigated ancestry proportions for the 1000 Genomes phase 3 populations clustered into six geographic groups with the objective of determining associations of geographically-partitioned genetic ancestry with fibroid status and fibroid traits in Black and White women from a large electronic health record (EHR) biorepository.

\section{Materials And Methods}

\section{Study Population}

BioVU fibroid case and control subjects were selected as previously described(Bray, Edwards, Wellons, Jones, Hartmann and Velez Edwards, 2017, Feingold-Link et al., 2014). Briefly, The BioVU repository is a collection of stored DNA linked to de-identified EHRs at Vanderbilt University Medical Center, a resource which currently includes more than 240,000 samples for the investigation of phenotype-genotype associations(Roden et al., 2008). Fibroid cases and controls were selected from female BioVU participants over the age of 18 with at least one record of pelvic imaging. Individuals with an International Classification of Disease, ninth revision (ICD-9) diagnostic code for uterine fibroid diagnosis were selected as cases ( $n=1,195$ White cases, 583 Black cases), while individuals without the code, a 
second pelvic image, and no history of hysterectomy, myomectomy, or uterine artery embolization were selected as controls ( $n=1,164$ White controls, 797 Black controls). A comparison with manually reviewed records indicated a $96 \%$ positive predictive value and a $98 \%$ negative predictive value. Measurements of fibroid characteristics were manually abstracted from pelvic imaging reports and surgical reports. These characteristics include fibroid volume ( $n=396$ White subjects, 450 Black subjects), largest dimension $(n=$ 579 White subjects, 450 Black subjects), and presence of multiple fibroids (i.e. single vs multiple, $n=356$ White single-fibroid subjects, 359 multiple-fibroid White subjects, 192 Black single-fibroid subjects, 258 multiple-fibroid Black subjects).

\section{Ethical approval}

The study was approved by the Institutional Review Board at Vanderbilt University Medical Center (\#110407).

\section{SNP genotyping and quality control}

Fibroid cases and controls were genotyped as previously described(Giri, Edwards, Hartmann, Torstenson, Wellons, Schreiner and Velez Edwards, 2017). Briefly, subjects were genotyped using the Affymetrix Axiom Biobank array (Affymetrix, Inc., Santa Clara, CA) and the Axiom World Array 3 (Affymetrix, Inc., Santa Clara, CA). DNA was purified and quantitated by PicoGreen (Invitrogen, Inc., Grand Island, NY). Standard quality control measures were applied using PLINK2(Chang et al., 2015). Sample exclusion criteria included genotypic duplicates, excess heterozygosity, call rate below $95 \%$, and discordance between genetically-inferred sex and database sex. Closely related individuals identified by inheritanceby-descent (IBD) sharing were removed. Variants with low call rate $(<95 \%)$ were excluded from subsequent analyses. Genotype data were pruned for linkage disequilibrium (LD) using a window size of 50 base pairs (bp) shifting by ten bp at an $\mathrm{r}^{2}$ threshold of 0.1 .

1000 Genomes reference genotype data were downloaded from the UCSC server (http://hgdownload.cse.ucsc.edu/gbdb/hg19/1000Genomes/phase3/). Genotype data for 1000 Genomes samples were pruned for LD using a window size of $50 \mathrm{bp}$ shifting by ten bp at an $\mathrm{r}^{2}$ threshold of 0.1 . Variants with low call rate $(<95 \%)$ were excluded from subsequent analyses. Genotype data were then randomly thinned to include 100,000 variants. For analysis of geographic ancestry proportions, LDpruned genotype data for cases and controls were merged separately for Black and White subjects with reference genotype data. Variants with low call rate $(<95 \%)$ in each merged set were excluded from subsequent analyses. Merged genotype data were then randomly thinned to include 100,000 variants.

\section{Assessment and cleaning of genetically-inferred reference ancestries}

1000 Genomes samples from each reference population $(n=26)$ were randomly partitioned into training and testing sets. Supervised ADMIXTURE(Alexander et al., 2009) analysis (K=26) specifying population for each training set and estimating ancestry proportions in each testing set was used to identify heterogenous populations. Analysis showed sharing within, but not between, populations corresponding 
to the five continental ancestries with two exceptions, sharing between Black and White populations and sharing between East and South Asian populations (Supplementary Figure 1). Populations were excluded from subsequent analysis if ancestry proportions for the specified training set population were below $60 \%$ in the testing set (Supplementary Table 1). Six 1000 Genomes reference populations were excluded from subsequent analysis due to heterogeneity. These populations included Americans of African Ancestry in the southwestern USA (ASW), Southern Han Chinese (CHS), British in England and Scotland (GBR), African Caribbeans in Barbados (ACB), Kinh in Ho Chi Minh City, Vietnam (KHV), and Indian Telugu from the UK (ITU) samples (Supplementary Table 1). Additionally, admixed American populations (Mexican Ancestry from Los Angeles, USA[MXL], Puerto Ricans from Puerto Rico [PUR], Colombians from Medellin, Colombia [CLM], and Peruvians from Lima, Peru [PEL]) were excluded from further analysis.

Genotype data for 1000 Genomes samples were analyzed using ADMIXTURE(Alexander, Novembre and Lange, 2009) at several $\mathrm{K}$ means to determine the maximum number of ancestries that could be resolved by the software. Cross-validation error decreased for $\mathrm{K}$ means between one and five, stabilized at $\mathrm{K}$ means of five to ten, and began to increase at $\mathrm{K}$ means greater than 10 (Supplementary Figure 2). Subjects from remaining 1000 Genomes populations were divided into six geographic populations. East African (EAFR) included Luhya in Webuye, Kenya (LWK) samples. West African included Gambian in Western Divisions in the Gambia (GWD), Esan in Nigeria (ESN), Mende in Sierra Leone (MSL), and Yoruba in Ibadan, Nigeria (YRI) samples. Northern European included Finnish in Finland (FIN) and Utah Residents (CEPH) with Northern and Western European ancestry (CEU) samples. Southern European included Iberian Population in Spain (IBS) and Toscani in Italia (TSI) samples. East Asian included Chinese Dai in Xishuangbanna, China (CDX), Han Chinese in Beijing, China (CHB), and Japanese in Tokyo, Japan (JPT) samples. South Asian included Punjabi from Lahore, Pakistan (PJL), Bengali from Bangladesh (BEB), Sri Lankan Tamil from the UK (STU), and Gujarati Indian from Houston, Texas (GIH) samples.

\section{Analysis of geographic ancestry proportions in BioVU}

Unsupervised ADMIXTURE analysis $(K=6)$ of 1000 Genomes reference genotype data from each merged set (Black women and White women) was performed and ancestry proportions for each of the six reference groups were calculated (Supplementary Tables 2 and 3). These ancestry proportions were then projected onto BioVU fibroid cases and control samples in ADMIXTURE using their genotype data from the respective merged sets. Mean ancestry proportions are presented in Table 1.

\section{Association of geographic ancestry proportions with fibroid status and fibroid traits}

Associations with global genetic ancestry proportions were computed using R(R Core Team, 2015). Dichotomous fibroid outcomes of fibroid case/control status and single vs multiple fibroids were modeled using logistic regression against each ancestry proportion separately for Black and White subjects. Continuous fibroid traits of fibroid volume and largest fibroid dimension were modeled using linear regression against each ancestry proportion separately for Black and White subjects. Continuous 
outcomes were $\log _{10}$ transformed for normality. All models were adjusted for age. Effect estimates are reported per $10 \%$ increase for a given inferred ancestry proportion.

\section{Results}

1000 Genomes samples were grouped in to EAFR, WAFR, NEUR, SEUR, EAS, and SAS and geneticallyinferred ancestry proportions were calculated for each of these geographic populations. Ancestry proportions were then projected onto Black and White BioVU fibroid case and control subjects and tested for association with fibroid status and fibroid characteristics. These analyses included a total of 3,739 individuals from two ethnicities, Black and White. Characteristics of study participants by ethnicity and case/control status are presented in Table 1.

White cases were 10 years younger with marginally higher body mass index (BMI) than White controls on average. The mean age among Black participants was younger than the mean age of White participants across both cases and controls (Cases: $40.5 \pm 13.6$ Black, $45.7 \pm 12.0$ White, Controls: $40.4 \pm 13.5$ Black, $55.6 \pm 18.9$ White). Average fibroid largest dimension was marginally higher for Black cases while fibroid volume was higher among White cases. SEUR ancestry proportion was largest among White participants, while EAFR, WAFR, and EAS proportions were $<5 \%$. EAFR and WAFR ancestry proportions were largest among Black participants, while EAS and SAS proportions were $<5 \%$.

Results of ancestry proportion associations with fibroid status and multiple fibroid status are provided in Figures 1-2 and Tables 2-3. Among White subjects, every $10 \%$ higher NEUR ancestry was protective for fibroids (OR=0.79, 95\% $\left.\mathrm{Cl}=0.66-0.94, P=8.00 \times 10^{-3}\right)$ and SAS ancestry was associated with fibroid risk ( $\mathrm{OR}=1.41,95 \% \mathrm{Cl}=1.02-1.94, P=0.04)$. In Black subjects, WAFR ancestry was associated with fibroid risk (OR=1.54, 95\% $\left.\mathrm{Cl}=1.23-1.92, P=1.79 \times 10^{-4}\right)$, EAFR ancestry was associated with risk of multiple fibroids $(\mathrm{OR}=1.63,95 \% \mathrm{Cl}=1.02-2.61, P=0.04)$, NEUR ancestry was protective for multiple fibroids $(\mathrm{OR}=0.45,95 \%$ $\mathrm{Cl}=0.23-0.87, P=0.02)$, and SEUR ancestry was protective for fibroids $(\mathrm{OR}=0.79,95 \% \mathrm{Cl}=0.67-0.95$, $P=0.01)$ and multiple fibroids ( $\mathrm{OR}=0.67,95 \% \mathrm{Cl}=0.46-0.97, P=0.04)$.

Results of ancestry proportion associations with fibroid characteristics are presented in Figures 3-4 and Tables 4-5. Among White subjects, WAFR ancestry was positively associated with fibroid volume $(\beta=0.60$ cubic centimeters $\left.\left(\mathrm{cm}^{3}\right), \mathrm{SE}=0.27, P=0.03\right)$ and largest dimension $(\beta=0.22$ centimeters $(\mathrm{cm}), \mathrm{SE}=0.10$, $P=0.03)$. In Black subjects, SAS ancestry was positively associated with fibroid volume $\left(\beta=0.75 \mathrm{~cm}^{3}\right.$, $\left.\mathrm{SE}=0.19, P=6.73 \times 10^{-5}\right)$ and largest dimension $\left(\beta=0.20 \mathrm{~cm}, \mathrm{SE}=0.07, P=3.00 \times 10^{-3}\right)$. EAS ancestry was not associated with any outcome in either group.

\section{Discussion}

We conducted association analyses of genetic ancestry corresponding to six biogeographic ancestries based on 1000 Genomes populations with fibroid status, single versus multiple fibroids, fibroid volume, and fibroid largest dimension. Our results demonstrate that fibroid risk and fibroid characteristics are 
influenced by genetic ancestry, with West African ancestry as a risk factor for fibroids, multiple fibroids, and fibroid size, European ancestry was protective against the development of fibroids, and Northern European ancestry was protective against the development of multiple fibroids. Previous admixture studies have reported increased fibroids risk associations with African ancestry, though these studies do not characterize ancestry proportions using a regional geographic reference inside Africa (Bray, Edwards, Wellons, Jones, Hartmann and Velez Edwards, 2017, Wise et al., 2012). The Asian ancestry proportions we observed in Black subjects are consistent with a previous study by Murray et al. examining continental ancestry proportions in Black individuals (Murray et al., 2010). A study by Richman et al. examining the association of continental ancestry proportions with lupus nephritis, another fibroproliferative disease, showed that the South Asian was the largest non-European ancestry proportion among White samples, which is consistent with our findings(Richman et al., 2012).

Two previous studies also investigated genetic ancestry and risk for fibroids. Both studies were performed exclusively in African ancestry individuals. In the Wise et al. 2013 study, European ancestry was inversely associated with risk of fibroids(Wise, Ruiz-Narvaez, Palmer, Cozier, Tandon, Patterson, Radin, Rosenberg and Reich, 2012). The authors suggested that genetic variation for fibroids differs between populations with and without African ancestry. Our study supports these results, with Northern and Southern European ancestry protective against multiple fibroids and Southern European ancestry protective against fibroids in African ancestry individuals. The other study, by Zhang et al., found similar percentages of European ancestry in cases and controls compared to the Wise et al. study; however, they failed to show a significant association between fibroids and percentage of European ancestry(Zhang et al., 2015). The lack of statistical significance in this study may be due to low power as it had a smaller sample size than both the Wise et al. and our study.

Fibroids are one of a group of diseases that vary widely in presentation but all share a disproportionate impact on individuals of African ancestry. Pathogenesis of fibroproliferative-based conditions, such as uterine fibroids, involves complex biological processes, including dysregulation of scarring and overgrowth of connective tissue (Hellwege et al., 2017, Huang and Ogawa, 2012). However, there is large heterogeneity in symptomology, fibroid location, and fibroid growth, both within and between patients, demonstrating the complexity of mechanisms underlying the development and growth of fibroids (Ciavattini et al., 2013, Commandeur et al., 2015). We have published evidence that polygenic selection has occurred at risk loci for several fibroproliferative traits between African and non-African populations, which may contribute to racial disparities in risk and severity (Hellwege et al., 2017). In these studies we demonstrated that across published GWAS of fibroproliferative diseases there is strong evidence of increasing selection among those of African ancestry when compared to those of non-African ancestry. It may be that fibroid risk alleles have pleiotropic effects on diseases (share common genetic risk factors) and this is the cause of the observed racial disparity in fibroproliferative diseases.

More research is needed in this area, as this study possesses limitations that must be addressed. The cohort from which the study population was obtained was well defined, as all women in the cohort all had pelvic imaging. Case status was based on a single ICD-9 code for fibroids. ICD codes are largely used 
for billing purposes and not specifically designed for research purposes. Reliance on these codes may lead to bias in results due to misclassification. However, a portion of the data was independently validated through manual chart abstraction. With the strong performance of the fibroid phenotype classification algorithm, the possibility of results being due to misclassification of the outcome is unlikely. While there is significant heritability for fibroids, environmental and lifestyle factors also play a role. Future studies should extend this investigation by looking at the role of non-genetic risk factors and their potential interaction with genetic ancestry.

Although ethnic disparities are well-documented, this study is unique in showing evidence of association of genetically-inferred geographic ancestry with fibroid status and fibroid traits and establishes that a portion of fibroid trait racial disparities are due to genetic differences between groups with varying ancestral geographic origins. Further investigation at the local ancestry and single variant levels may yield novel insights about disease architecture and genetic mechanisms underlying racial/ethnic disparities in fibroid risk. Together, these analyses may provide insight into the geographic factors underlying the origin of fibroid risk variants.

\section{Declarations}

\section{FUNDING}

The BioVU dataset used for the analyses described was obtained from Vanderbilt University Medical Center's BioVU which is supported by institutional funding and by the Vanderbilt CTSA grant ULTR000445 from NCATS/NIH. This work was supported in part by National Institute of Health grants R01HD074711, R01HD093671, and R03HD078567 to D.R.V.E. J.N.H. was supported by K12HD04348 (PI K.E. Hartmann). J.M.K. and E.A.J. were supported by the National Human Genome Research Institute training grant 5T32HG008341.

\section{CONFLICT OF INTERESTS}

There are no conflicts of interest relevant to this article.

\section{DATA AVAILABILITY}

The data underlying this article will be shared on reasonable request to the corresponding author.

\section{CODE AVAILABILITY}

The code underlying this article will be shared on reasonable request to the corresponding author.

\section{AUTHOR CONTRIBUTIONS}

Jacob M. Keaton assisted with analysis and drafting manuscript. Elizabeth A. Jasper assisted with analysis and drafting manuscript. Jacklyn N. Hellwege assisted with analysis and data quality control and edited the final draft. Sarah H. Jones assisted with data management and edited final draft. Eric S. 
Torstenson assisted with data management and quality controls and edited final draft. Todd L. Edwards helped develop the study design and analysis plan and edited the manuscript. Digna R. Velez Edwards helped develop the study design and analysis plan and edited the manuscript.

\section{ETHICS APPROVAL}

The study was approved by the Institutional Review Board at Vanderbilt University Medical Center (\#110407).

\section{FUNDING}

We have no competing interests. The BioVU dataset used for the analyses described was obtained from Vanderbilt University Medical Center's BioVU which is supported by institutional funding and by the Vanderbilt CTSA grant ULTR000445 from NCATS/NIH. D.R.V.E. was supported by National Institute of Health grants R01HD074711, R01HD093671, and R03HD078567. J.N.H. was supported by K12HD04348 (PI K.E. Hartmann). J.M.K. and E.A.J. were supported by the NHGRI training grant T32HG008341.

\section{CONFLICTS OF INTEREST}

All authors have no conflicts of interest to report.

\section{References}

1. Alexander DH, Novembre J, Lange K. Fast model-based estimation of ancestry in unrelated individuals. Genome Res 2009;19: 1655-1664.

2. August P, Suthanthiran M. Transforming growth factor beta and progression of renal disease. Kidney Int Supp/ 2003: S99-104.

3. Baird DD, Dunson DB, Hill MC, Cousins D, Schectman JM. High cumulative incidence of uterine leiomyoma in black and white women: ultrasound evidence. Am J Obstet Gynecol 2003;188: 100107.

4. Barnes KC, Grant AV, Hansel NN, Gao P, Dunston GM. African Americans with asthma: genetic insights. Proc Am Thorac Soc 2007;4: 58-68.

5. Bray MJ, Edwards TL, Wellons MF, Jones SH, Hartmann KE, Velez Edwards DR. Admixture mapping of uterine fibroid size and number in African American women. Fertil Steril 2017;108: 1034-1042 e1026.

6. Cardozo ER, Clark AD, Banks NK, Henne MB, Stegmann BJ, Segars JH. The estimated annual cost of uterine leiomyomata in the United States. Am J Obstet Gynecol 2012;206: 211 e211-219.

7. Chang CC, Chow CC, Tellier LC, Vattikuti S, Purcell SM, Lee JJ. Second-generation PLINK: rising to the challenge of larger and richer datasets. Gigascience 2015;4: 7.

8. Ciavattini A, Di Giuseppe J, Stortoni P, Montik N, Giannubilo SR, Litta P, Islam MS, Tranquilli AL, Reis FM, Ciarmela P. Uterine fibroids: pathogenesis and interactions with endometrium and 
endomyometrial junction. Obstet Gynecol Int 2013;2013: 173184.

9. Commandeur AE, Styer AK, Teixeira JM. Epidemiological and genetic clues for molecular mechanisms involved in uterine leiomyoma development and growth. Hum Reprod Update 2015;21: 593-615.

10. Cramer SF, Patel A. The frequency of uterine leiomyomas. Am J Clin Pathol 1990;94: 435-438.

11. Dustan HP. Growth factors and racial differences in severity of hypertension and renal diseases. Lancet 1992;339: 1339-1340.

12. Feingold-Link L, Edwards TL, Jones S, Hartmann KE, Velez Edwards DR. Enhancing uterine fibroid research through utilization of biorepositories linked to electronic medical record data. $J$ Womens Health (Larchmt) 2014;23: 1027-1032.

13. Flake GP, Andersen J, Dixon D. Etiology and pathogenesis of uterine leiomyomas: a review. Environ Health Perspect 2003;111: 1037-1054.

14. Giri A, Edwards TL, Hartmann KE, Torstenson ES, Wellons M, Schreiner PJ, Velez Edwards DR. African genetic ancestry interacts with body mass index to modify risk for uterine fibroids. PLoS Genet 2017;13: e1006871.

15. Hellwege JN, Torstenson ES, Russell SB, Edwards TL, Velez Edwards DR. Evidence of selection as a cause for racial disparities in fibroproliferative disease. PLoS One 2017;12: e0182791.

16. Huang C, Ogawa R. Fibroproliferative disorders and their mechanobiology. Connect Tissue Res 2012;53: 187-196.

17. Kjerulff KH, Langenberg P, Seidman JD, Stolley PD, Guzinski GM. Uterine leiomyomas. Racial differences in severity, symptoms and age at diagnosis. J Reprod Med 1996;41: 483-490.

18. Laughlin SK, Baird DD, Savitz DA, Herring AH, Hartmann KE. Prevalence of uterine leiomyomas in the first trimester of pregnancy: an ultrasound-screening study. Obstet Gynecol 2009;113: 630-635.

19. Lester LA, Rich SS, Blumenthal MN, Togias A, Murphy S, Malveaux F, Miller ME, Dunston GM, Solway $\mathrm{J}$, Wolf RL et al. Ethnic differences in asthma and associated phenotypes: collaborative study on the genetics of asthma. J Allergy Clin Immunol 2001;108: 357-362.

20. Lippman SA, Warner M, Samuels S, Olive D, Vercellini P, Eskenazi B. Uterine fibroids and gynecologic pain symptoms in a population-based study. Fertil Steril 2003;80: 1488-1494.

21. Marshall LM, Spiegelman D, Barbieri RL, Goldman MB, Manson JE, Colditz GA, Willett WC, Hunter DJ. Variation in the incidence of uterine leiomyoma among premenopausal women by age and race. Obstet Gynecol 1997;90: 967-973.

22. Mayes MD, Lacey JV, Jr., Beebe-Dimmer J, Gillespie BW, Cooper B, Laing TJ, Schottenfeld D. Prevalence, incidence, survival, and disease characteristics of systemic sclerosis in a large US population. Arthritis Rheum 2003;48: 2246-2255.

23. Morris DA, Peracha MO, Shin DH, Kim C, Cha SC, Kim YY. Risk factors for early filtration failure requiring suture release after primary glaucoma triple procedure with adjunctive mitomycin. Arch Ophthalmol 1999;117: 1149-1154. 
24. Murray T, Beaty TH, Mathias RA, Rafaels N, Grant AV, Faruque MU, Watson HR, Ruczinski I, Dunston GM, Barnes KC. African and non-African admixture components in African Americans and an African Caribbean population. Genet Epidemiol 2010;34: 561-568.

25. Newth CJ, Meert KL, Clark AE, Moler FW, Zuppa AF, Berg RA, Pollack MM, Sward KA, Berger JT, Wessel DL et al. Fatal and near-fatal asthma in children: the critical care perspective. $J$ Pediatr 2012;161: 214-221 e213.

26. Nickel R, Beck LA, Stellato C, Schleimer RP. Chemokines and allergic disease. J Allergy Clin Immunol 1999;104: 723-742.

27. Niessen FB, Spauwen PH, Schalkwijk J, Kon M. On the nature of hypertrophic scars and keloids: a review. Plast Reconstr Surg 1999;104: 1435-1458.

28. Polednak AP. Connective tissue responses in blacks in relation to disease: further observations. Am J Phys Anthropol 1987;74: 357-371.

29. R Core Team. R: A language and environment for statistical computing. 2015. R Foundation for Statistical Computing, Vienna, Austria.

30. Racette L, Wilson MR, Zangwill LM, Weinreb RN, Sample PA. Primary open-angle glaucoma in blacks: a review. Surv Ophthalmol 2003;48: 295-313.

31. Richman IB, Taylor KE, Chung SA, Trupin L, Petri M, Yelin E, Graham RR, Lee A, Behrens TW, Gregersen PK et al. European genetic ancestry is associated with a decreased risk of lupus nephritis. Arthritis Rheum 2012;64: 3374-3382.

32. Roden DM, Pulley JM, Basford MA, Bernard GR, Clayton EW, Balser JR, Masys DR. Development of a large-scale de-identified DNA biobank to enable personalized medicine. Clin Pharmacol Ther 2008;84: 362-369.

33. Ross RK, Pike MC, Vessey MP, Bull D, Yeates D, Casagrande JT. Risk factors for uterine fibroids: reduced risk associated with oral contraceptives. Br Med J (Clin Res Ed) 1986;293: 359-362.

34. Russell SB, Smith JC, Huang M, Trupin JS, Williams SM. Pleiotropic Effects of Immune Responses Explain Variation in the Prevalence of Fibroproliferative Diseases. PLoS Genet 2015;11: e1005568.

35. Ryan GL, Syrop CH, Van Voorhis BJ. Role, epidemiology, and natural history of benign uterine mass lesions. Clin Obstet Gynecol 2005;48: 312-324.

36. Rybicki BA, Maliarik MJ, Major M, Popovich J, Jr., lannuzzi MC. Epidemiology, demographics, and genetics of sarcoidosis. Semin Respir Infect 1998;13: 166-173.

37. Sato F, Mori M, Nishi M, Kudo R, Miyake H. Familial aggregation of uterine myomas in Japanese women. J Epidemiol 2002;12: 249-253.

38. Suthanthiran M, Li B, Song JO, Ding R, Sharma VK, Schwartz JE, August P. Transforming growth factor-beta 1 hyperexpression in African-American hypertensives: A novel mediator of hypertension and/or target organ damage. Proc Natl Acad Sci U S A 2000;97: 3479-3484.

39. Vikhlyaeva EM, Khodzhaeva ZS, Fantschenko ND. Familial predisposition to uterine leiomyomas. Int J Gynaecol Obstet 1995;51: 127-131. 
40. Wallach EE, Vlahos NF. Uterine myomas: an overview of development, clinical features, and management. Obstet Gynecol 2004;104: 393-406.

41. Wechter ME, Stewart EA, Myers ER, Kho RM, Wu JM. Leiomyoma-related hospitalization and surgery: prevalence and predicted growth based on population trends. Am J Obstet Gynecol 2011;205: 492 e491-495.

42. Whiteman MK, Hillis SD, Jamieson DJ, Morrow B, Podgornik MN, Brett KM, Marchbanks PA. Inpatient hysterectomy surveillance in the United States, 2000-2004. Am J Obstet Gynecol 2008;198: 34 e3137.

43. Wise LA, Ruiz-Narvaez EA, Palmer JR, Cozier YC, Tandon A, Patterson N, Radin RG, Rosenberg L, Reich D. African ancestry and genetic risk for uterine leiomyomata. Am J Epidemiol 2012;176: 11591168.

44. Zhang $\mathrm{K}$, Wiener $\mathrm{H}$, Aissani $\mathrm{B}$. Admixture mapping of genetic variants for uterine fibroids. $J$ Hum Genet 2015;60: 533-538.

45. Zimmermann A, Bernuit D, Gerlinger C, Schaefers M, Geppert K. Prevalence, symptoms and management of uterine fibroids: an international internet-based survey of 21,746 women. $B M C$ Womens Health 2012;12: 6.

\section{Tables}

Table 1. Demographics of the study participants 


\begin{tabular}{|c|c|c|c|c|}
\hline Characteristic & European & European & African & African \\
\hline \multirow[t]{3}{*}{ mean $( \pm S D)$} & Ancestry & Ancestry & Ancestry & Ancestry \\
\hline & Cases & Comilio & Cases & Controls \\
\hline & $(N=1,195)$ & & $(\mathrm{N}=583)$ & $(N=797)$ \\
\hline Age, years & $45.7( \pm 12.0)$ & $55.6( \pm 18.9)$ & $\begin{array}{l}40.5 \\
( \pm 13.6)\end{array}$ & $\begin{array}{l}40.4 \\
( \pm 13.5)\end{array}$ \\
\hline $\mathrm{BMl}, \mathrm{kg} / \mathrm{m}^{2}$ & $29.1( \pm 7.7)$ & $28.0( \pm 7.2)$ & $\begin{array}{l}28.1 \\
( \pm 15.3)\end{array}$ & $\begin{array}{l}28.1 \\
( \pm 15.3)\end{array}$ \\
\hline Fibroid largest dimension, cm & $3.85( \pm 2.74)$ & - & $\begin{array}{l}3.99 \\
( \pm 2.90)\end{array}$ & - \\
\hline Fibroid volume, $\mathrm{cm}^{3}$ & $\begin{array}{l}56.5 \\
( \pm 122.4)\end{array}$ & - & $\begin{array}{l}48.2 \\
( \pm 139.2)\end{array}$ & - \\
\hline \multicolumn{5}{|l|}{$\begin{array}{l}\text { Genetic ancestry proportions } \\
\text { mean }( \pm S D)\end{array}$} \\
\hline EAFR & $0.01( \pm 0.02)$ & $0.01( \pm 0.01)$ & $\begin{array}{l}0.38 \\
( \pm 0.04)\end{array}$ & $\begin{array}{l}0.38 \\
( \pm 0.05)\end{array}$ \\
\hline WAFR & $0.01( \pm 0.02)$ & $0.00( \pm 0.02)$ & $\begin{array}{l}0.35 \\
( \pm 0.04)\end{array}$ & $\begin{array}{l}0.34 \\
( \pm 0.05)\end{array}$ \\
\hline NEUR & $0.25( \pm 0.06)$ & $0.26( \pm 0.04)$ & $\begin{array}{l}0.07 \\
( \pm 0.03)\end{array}$ & $0.07(0.03)$ \\
\hline SEUR & $0.60( \pm 0.05)$ & $0.60( \pm 0.04)$ & $\begin{array}{l}0.12 \\
( \pm 0.05)\end{array}$ & $\begin{array}{l}0.13 \\
( \pm 0.07)\end{array}$ \\
\hline EAS & $0.03( \pm 0.02)$ & $0.03( \pm 0.03)$ & $\begin{array}{l}0.04 \\
( \pm 0.02)\end{array}$ & $\begin{array}{l}0.04 \\
( \pm 0.02)\end{array}$ \\
\hline SAS & $0.11( \pm 0.04)$ & $0.10( \pm 0.02)$ & $\begin{array}{l}0.04 \\
( \pm 0.02)\end{array}$ & $\begin{array}{l}0.04 \\
( \pm 0.02)\end{array}$ \\
\hline
\end{tabular}

$\mathrm{SD}$ - standard deviation; $\mathrm{kg} / \mathrm{m}^{2}$ - kilograms per meter squared; $\mathrm{cm}$ - centimeters; EAFR - East African; WAFR - West African; NEUR - Northern European; SEUR - Southern European; EAS - East Asian; SAS South Asian

Table 2. Ancestry associations with dichotomous fibroid traits in European ancestry individuals 


\begin{tabular}{|c|c|c|c|c|}
\hline & \multicolumn{2}{|c|}{$\begin{array}{l}\text { Fibroid Status } \\
\text { (Cases }=1,195, \text { Controls }=1,164)\end{array}$} & \multicolumn{2}{|c|}{$\begin{array}{l}\text { Multiple Fibroids } \\
\text { (Multiple }=359, \text { Single }=356 \text { ) }\end{array}$} \\
\hline & OR $(95 \% \mathrm{Cl})$ & P-value & OR (95\% Cl) & P-value \\
\hline EAFR & $1.58(0.89-2.80)$ & $1.20 \times 10 \rrbracket^{1}$ & $1.26(0.43-3.70)$ & $6.73 \times 10 \otimes^{1}$ \\
\hline WAFR & $1.41(0.83-2.40)$ & $2.00 \times 10 \rrbracket^{1}$ & $1.57(0.45-5.43)$ & $4.75 \times 10 \otimes^{1}$ \\
\hline NEUR & $0.79(0.66-0.94)$ & $8.00 \times 10 \rrbracket^{3}$ & $0.87(0.65-1.18)$ & $3.84 \times 10 \rrbracket^{1}$ \\
\hline SEUR & $1.10(0.91-1.33)$ & $3.14 \times 10 \otimes^{1}$ & $1.16(0.84-1.62)$ & $3.66 \times 10 \rrbracket^{1}$ \\
\hline EAS & $0.86(0.63-1.16)$ & $3.24 \times 10 \rrbracket^{1}$ & $0.92(0.43-1.95)$ & $8.25 \times 10 \otimes^{1}$ \\
\hline SAS & $1.41(1.02-1.94)$ & $3.70 \times 10 \rrbracket^{2}$ & $0.94(0.62-1.44)$ & $7.89 \times 10 \bigotimes^{1}$ \\
\hline
\end{tabular}

OR - odds ratio; $\mathrm{Cl}$ - confidence interval; EAFR - East African; WAFR - West African; NEUR - Northern European; SEUR - Southern European; EAS - East Asian; SAS - South Asian. Significant associations shown in bold.

Table 3. Ancestry associations with dichotomous fibroid traits in African ancestry individuals

\begin{tabular}{|c|c|c|c|c|}
\hline & \multicolumn{2}{|c|}{$\begin{array}{l}\text { Fibroid Status } \\
\text { (Cases }=583, \text { Controls }=797 \text { ) }\end{array}$} & \multicolumn{2}{|c|}{$\begin{array}{l}\text { Multiple Fibroids } \\
\text { (Multiple }=258, \text { Single }=192 \text { ) }\end{array}$} \\
\hline & OR (95\% Cl) & P-value & OR $(95 \% \mathrm{Cl})$ & P-value \\
\hline EAFR & $1.00(0.79-1.25)$ & $9.82 \times 10 \rrbracket^{1}$ & $1.63(1.02-2.61)$ & $4.20 \times 10 \rrbracket^{2}$ \\
\hline WAFR & $1.54(1.23-1.92)$ & $1.79 \times 10 \rrbracket^{4}$ & $1.45(0.91-2.30)$ & $1.19 \times 10 \rrbracket^{1}$ \\
\hline NEUR & $1.01(0.72-1.40)$ & $9.68 \times 10 \otimes^{1}$ & $0.45(0.23-0.87)$ & $1.80 \times 10 \rrbracket^{2}$ \\
\hline SEUR & $0.79(0.67-0.95)$ & $1.10 \times 10 \bigotimes^{2}$ & $0.67(0.46-0.97)$ & $3.50 \times 10 \rrbracket^{2}$ \\
\hline EAS & $1.08(0.61-1.93)$ & $7.87 \times 10 \otimes^{1}$ & $1.72(0.54-5.52)$ & $3.62 \times 10 \rrbracket^{1}$ \\
\hline SAS & $0.58(0.32-1.05)$ & $7.10 \times 10 \rrbracket^{2}$ & $1.23(0.53-2.89)$ & $6.28 \times 10 \rrbracket^{1}$ \\
\hline
\end{tabular}

OR - odds ratio; $\mathrm{Cl}$ - confidence interval; EAFR - East African; WAFR - West African; NEUR - Northern European; SEUR - Southern European; EAS - East Asian; SAS - South Asian. Significant associations shown in bold.

Table 4. Ancestry associations with continuous fibroid traits in European ancestry individuals 


\begin{tabular}{|c|c|c|c|c|}
\hline & \multicolumn{2}{|l|}{$\begin{array}{l}\text { Volume } \\
(\mathrm{N}=396)\end{array}$} & \multicolumn{2}{|c|}{$\begin{array}{l}\text { Largest Dimension } \\
(\mathrm{N}=579)\end{array}$} \\
\hline & BETA (SE) & P-value & BETA (SE) & P-value \\
\hline EAFR & $0.43(0.26)$ & $9.80 \times 10 \rrbracket^{2}$ & $0.16(0.09)$ & $8.40 \times 10 \rrbracket^{2}$ \\
\hline WAFR & $0.60(0.27)$ & $2.80 \times 10 \rrbracket^{2}$ & $0.22(0.10)$ & $2.90 \times 10 \mathrm{X}^{2}$ \\
\hline NEUR & $-0.04(0.09)$ & $6.52 \times 10 \otimes^{1}$ & $-0.01(0.03)$ & $7.96 \times 10 \rrbracket^{1}$ \\
\hline SEUR & $-0.12(0.09)$ & $1.94 \times 10 \otimes^{1}$ & $-0.03(0.03)$ & $2.66 \times 10 \rrbracket^{1}$ \\
\hline EAS & $0.24(0.33)$ & $4.71 \times 10 \otimes^{1}$ & $-0.03(0.09)$ & $6.92 \times 10 \otimes^{1}$ \\
\hline SAS & $0.04(0.12)$ & $7.55 \times 10 \otimes^{1}$ & $0.02(0.04)$ & $6.86 \times 10 \bigotimes^{1}$ \\
\hline
\end{tabular}

BETA - effect; SE - standard err; EAFR - East African; WAFR - West African; NEUR - Northern European; SEUR - Southern European; EAS - East Asian; SAS - South Asian. Significant associations shown in bold.

Table 5. Ancestry associations with continuous fibroid traits in African ancestry individuals

\begin{tabular}{|c|c|c|c|c|}
\hline & \multicolumn{2}{|l|}{$\begin{array}{l}\text { Volume } \\
(\mathrm{N}=450)\end{array}$} & \multicolumn{2}{|c|}{$\begin{array}{l}\text { Largest Dimension } \\
(\mathrm{N}=450)\end{array}$} \\
\hline & BETA (SE) & P-value & BETA (SE) & P-value \\
\hline EAFR & $0.12(0.10)$ & $2.54 \times 10 \otimes 1$ & $0.03(0.04)$ & $4.90 \times 10 \otimes^{1}$ \\
\hline WAFR & $-0.07(0.10)$ & $4.94 \times 10 \otimes^{1}$ & $0.03(0.04)$ & $3.77 \times 10 \otimes^{1}$ \\
\hline NEUR & $-0.23(0.15)$ & $1.24 \times 10 \otimes^{1}$ & $-0.08(0.05)$ & $1.19 \times 10 \rrbracket^{1}$ \\
\hline SEUR & $-0.07(0.08)$ & $3.93 \times 10 \otimes^{1}$ & $-0.04(0.03)$ & $1.65 \times 10 \rrbracket^{1}$ \\
\hline EAS & $-0.31(0.25)$ & $2.23 \times 10 \rrbracket^{1}$ & $-0.08(0.09)$ & $3.73 \times 10 \otimes^{1}$ \\
\hline SAS & $0.75(0.19)$ & $6.73 \times 10$ 呕 & $0.20(0.07)$ & $3.00 \times 10 \rrbracket^{3}$ \\
\hline
\end{tabular}

BETA - effect; SE - standard err; EAFR - East African; WAFR - West African; NEUR - Northern European; SEUR - Southern European; EAS - East Asian; SAS - South Asian. Significant associations shown in bold. 


\section{EAFR}

WAFR

NEUR

SEUR

EAS

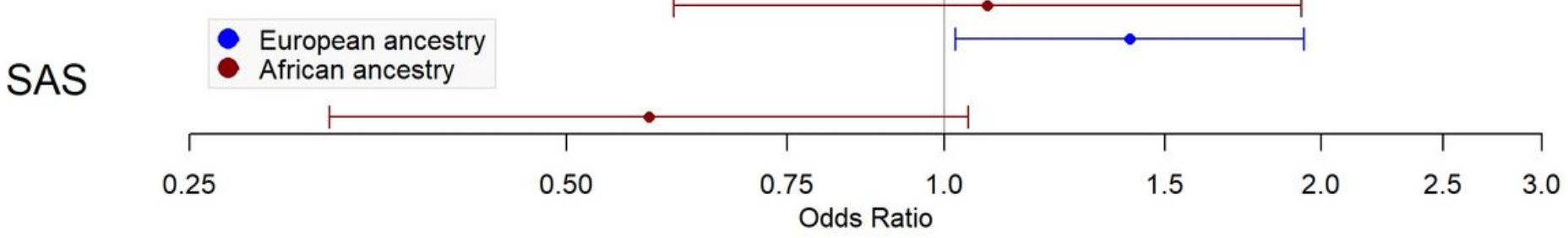

\section{Figure 1}

Ancestry associations with fibroid status. Forest plot of odds ratios and confidence intervals for association of fibroid status with 6 biogeographic ancestries in European ancestry (blue) and African ancestry (red). EAFR - East African; WAFR - West African; NEUR - Northern European; SEUR - Southern European; EAS - East Asian; SAS - South Asian

EAFR

WAFR

NEUR

SEUR

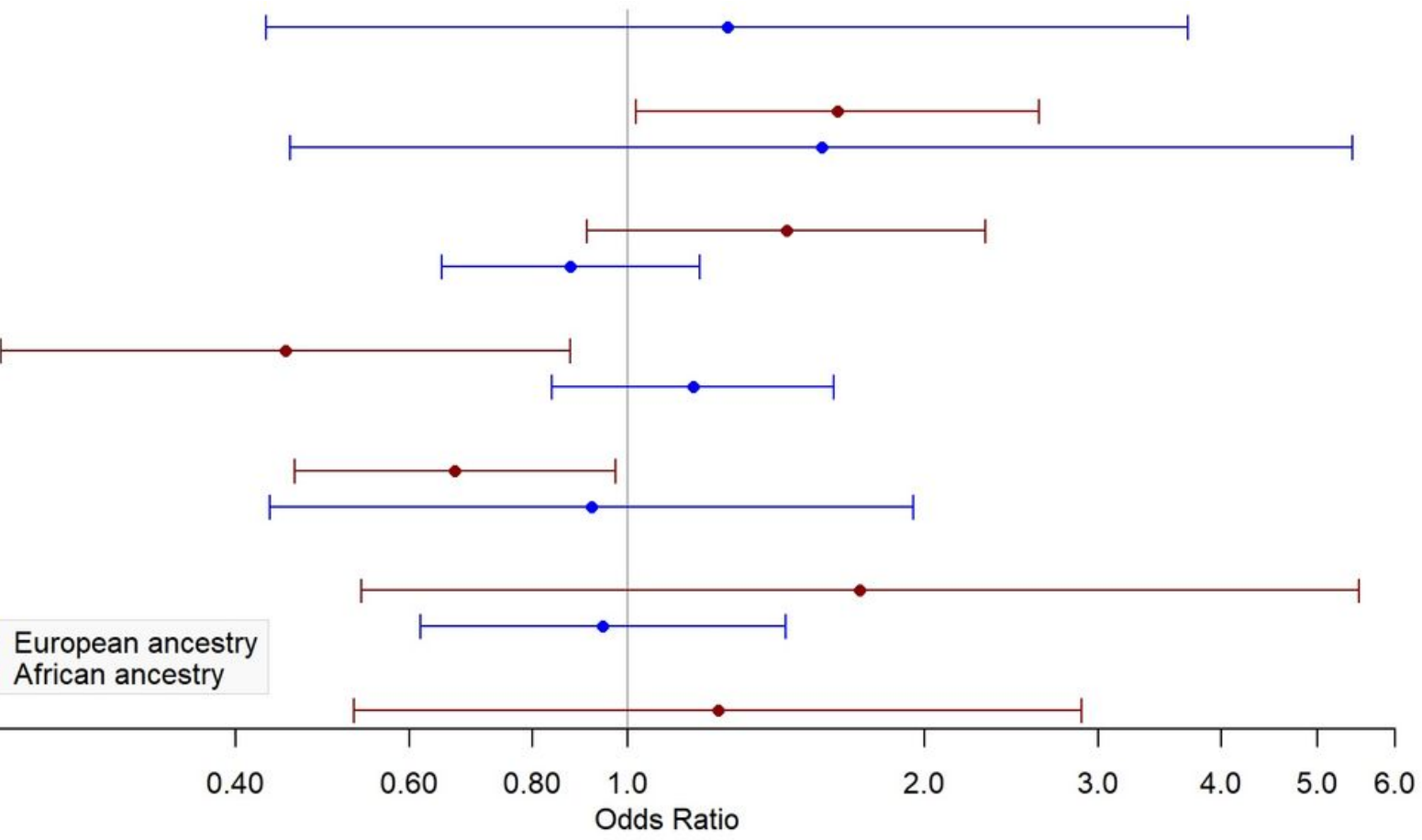

EAS

SAS

\section{Figure 2}


Ancestry associations with multiple fibroid status. Forest plot of odds ratios and confidence intervals for association of multiple fibroid status with 6 biogeographic ancestries in European ancestry (blue) and African ancestry (red). EAFR - East African; WAFR - West African; NEUR - Northern European; SEUR Southern European; EAS - East Asian; SAS - South Asian

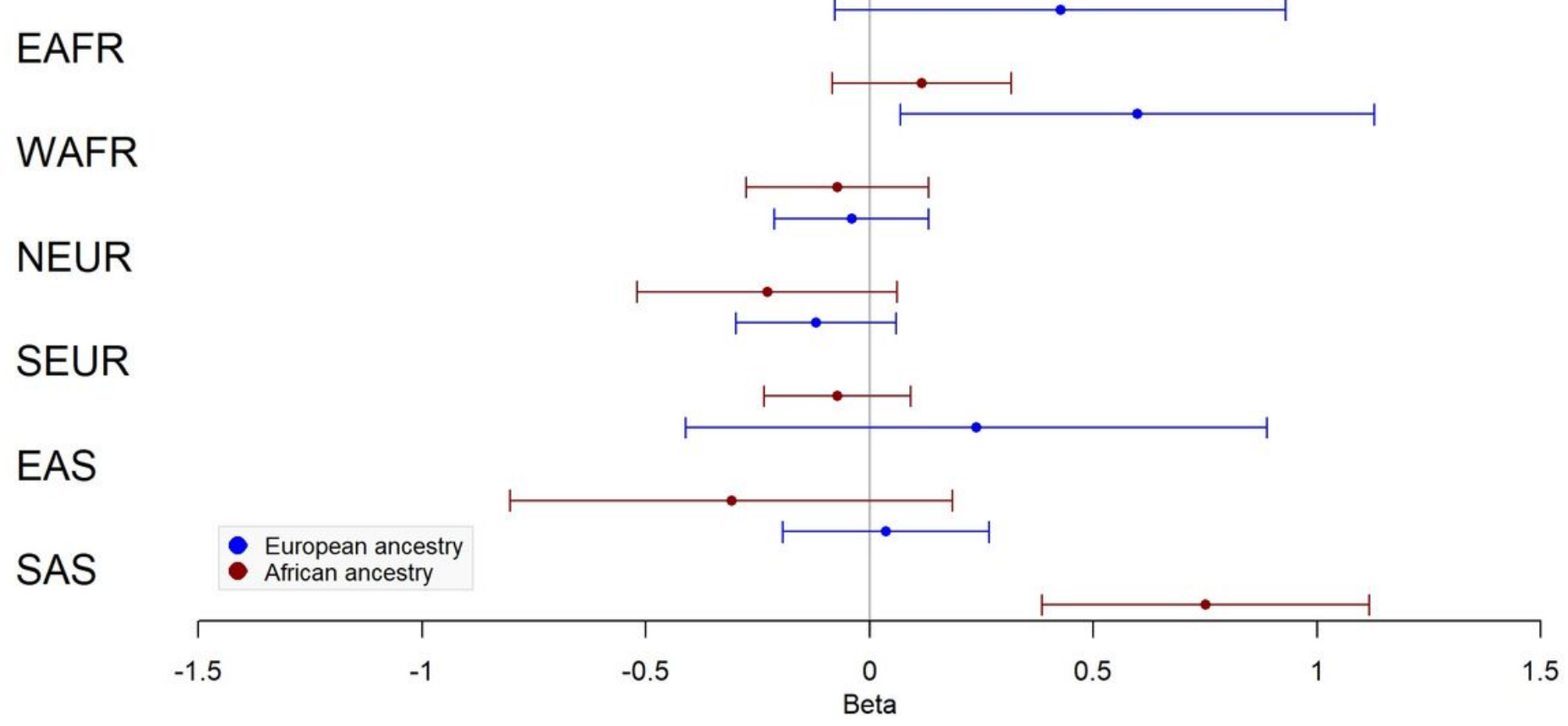

\section{Figure 3}

Ancestry associations with fibroid volume. Forest plot of effect and standard error for association of fibroid volume with 6 biogeographic ancestries in European ancestry (blue) and African ancestry (red). EAFR - East African; WAFR - West African; NEUR - Northern European; SEUR - Southern European; EAS - East Asian; SAS - South Asian

\section{EAFR}

WAFR

NEUR

SEUR

EAS

SAS

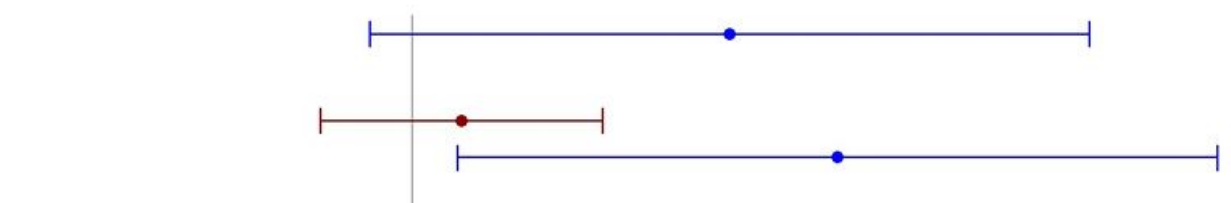




\section{Figure 4}

Ancestry associations with fibroid largest dimension. Forest plot of effect and standard error for association of fibroid largest dimension with six biogeographic ancestries in European ancestry (blue) and African ancestry (red). EAFR - East African; WAFR - West African; NEUR - Northern European; SEUR - Southern European; EAS - East Asian; SAS - South Asian

\section{Supplementary Files}

This is a list of supplementary files associated with this preprint. Click to download.

- SupplementaryTablesandFigures.docx 